\title{
Clinical value of blood related indexes in the diagnosis of bacterial infectious pneumonia in children
}

\author{
Hai-Han Zheng, Yun Xiang, Yan Wang, Qing-Song Zhao, Rui Fang, Rui Dai \\ Department of Pediatrics, The Second Affiliated Hospital of Anhui Medical University, Hefei, China \\ Contributions: (I) Conception and design: HH Zheng; (II) Administrative support: Y Xiang; (III) Provision of study materials or patients: Y Wang; (IV) \\ Collection and assembly of data: HH Zheng; (V) Data analysis and interpretation: R Fang; (VI) Manuscript writing: All authors; (VII) Final approval \\ of manuscript: All authors. \\ Correspondence to: Hai-Han Zheng. Department of Pediatrics, The Second Affiliated Hospital of Anhui Medical University, Hefei 230601, China. \\ Email: zhh_2839@163.com.
}

Background: This study sought to explore the value of hematological indexes [i.e., the neutrophil count/ lymphocyte count ratio (NLR), the platelet count/lymphocyte count ratio (PLR), and red cell distribution width $(\mathrm{RDW})$ index] in the diagnosis of bacterial infectious pneumonia in children.

Methods: Fifty cases of mycoplasma infectious pneumonia, 50 cases of bacterial infectious pneumonia and 50 healthy children were enrolled in this study. The differences between the NLR, PLR, and RDW index values in each group were compared using the Mann-Whitney test. The correlation coefficients of the NLR, PLR, and RDW index with the interleukin-6 (IL-6) and procalcitonin (PCT) were analyzed using the Spearman's rank test. The specificity and sensitivity of the NLR, PLR, and RDW index in the diagnosis of bacterial pneumonia in children were evaluated by receiver operating characteristic (ROC) curves.

Results: The NLR value of the children with bacterial infectious pneumonia was significantly higher than that of the children with mycoplasma infectious pneumonia $(\mathrm{P}<0.05)$ and healthy children $(\mathrm{P}<0.05)$, while the PLR value of the children with bacterial infectious pneumonia was significantly lower than that of the children with mycoplasma infectious pneumonia $(\mathrm{P}<0.05)$ and healthy children $(\mathrm{P}<0.05)$. There was no significant difference in the RDW index values of the healthy control children and the children with mycoplasma infectious pneumonia and bacterial infectious pneumonia $(\mathrm{P}>0.05)$. There was a positive correlation between NLR and serum IL-6 $(\mathrm{R}=0.203$; $\mathrm{P}=0.041)$, and a negative correlation between PLR and serum PCT $(\mathrm{R}=-0.291 ; \mathrm{P}=0.037)$. In addition, there was no significant correlation between the RDW index and serum IL-6, and the RDW index and serum PCT in children with bacterial infectious pneumonia. When the 3 indicators were each used to differentiate between healthy children and children with bacterial pneumonia, the area under the PLR curve was the largest for the ROC curve $[0.898,95 \%$ confidence interval (CI): 0.815-0.953]. In the differential diagnosis of mycoplasma pneumonia and bacterial pneumonia, the area under the PLR curve was also the largest (0.803, 95\% CI: 0.577-0.780).

Conclusions: The PLR has clinical value in the diagnosis of bacterial infectious pneumonia in children.

Keywords: Red blood cell distribution width; neutrophil count/lymphocyte count ratio (NLR); platelet count/ lymphocyte count ratio (PLR); children with pneumonia

Submitted Nov 10, 2021. Accepted for publication Dec 30, 2021.

doi: $10.21037 /$ tp-21-568

View this article at: https://dx.doi.org/10.21037/tp-21-568 


\section{Introduction}

Children's pneumonia is the most common respiratory disease, and is mostly caused by pathogenic microorganisms, such as bacteria and viruses. The diagnostic criteria for pneumonia in adults and children are the same. However, the morbidity, mortality and disability of pneumonia in children are higher the in adults. As children's respiratory systems and immune functions are not mature, if left untreated or if treated improperly, heart failure, toxic encephalopathy, shock and so on may result (1). Cavitary necrosis occurs in $4 \%$ of patients $(2,3)$. Statistics show that severe pneumonia in children accounts for $7 \%$ to $13 \%$ of children's pneumonia (4). Clinically, the early identification of the infection type and the selection of the correct treatment will not only ensure a better prognosis, but will also reduce complications, reduce the burden placed on patients, and shorten hospital stays. Recent studies have linked elevated levels of red cell distribution width (RDW) to lung diseases, such as chronic obstructive pulmonary disease and community-acquired pneumonia (5).

The neutrophil to lymphocyte ratio (NLR) and the platelet to lymphocyte ratio (PLR) reflect the degree of inflammation and the state of immunity (6). However, it is not clear whether the NLR, PLR, and RDW index can be used to diagnose bacterial pneumonia in children. Thus, this study sought to compare differences in the NLR, PLR, and RDW index values between children with pneumonia caused by mycoplasma infection and children with pneumonia caused by bacteria infection. The correlation coefficients between the NLR, PLR, RDW index, interleukin-6 (IL-6) levels, and procalcitonin (PCT) levels were analyzed using the Spearman's rank test. Receiver operating characteristic (ROC) curves were used to evaluate the clinical value of the NLR, PLR, and RDW index in the diagnosis of bacterial pneumonia in children. The results of this study can be used to guide the clinical diagnosis and treatment of bacterial infectious pneumonia.

We present the following article in accordance with the STARD reporting checklist (available at https:// tp.amegroups.com/article/view/10.21037/tp-21-568/rc).

\section{Methods}

\section{Subjects}

From January 2020 to November 2021, 50 patients with bacterial pneumonia and 50 patients with mycoplasma pneumonia were diagnosed at our hospital and enrolled in this random study. Fifty healthy children in the same period were selected as the control group. The inclusion criteria for the children reflected the relevant diagnostic criteria set out in the Criteria for Diagnosis and Treatment of Children's Community-acquired Pneumonia (2019 edition) and the Expert Consensus on Laboratory Diagnosis and Clinical Practice of Mycoplasma Pneumoniae Infection in Children (2019). The clinical signs of bacterial pneumonia are fever, cough, and fixed moist rales in the lungs, and its diagnosis is based on lung imaging. Mycoplasma infection pneumonia is detected by mycoplasma antibody indicators, and accompanied by lung imaging changes. Patients were excluded from the study if they met any of the following exclusion criteria: (I) had a primary immunodeficiency disease or childhood hematological malignancies; (II) had other infectious diseases; and/or (III) had previously been administered antibiotics or undergone glucocorticoid therapy.

The bacterial pneumonia group comprised 28 male and 22 female children aged $6.4 \pm 3.5$ years. The mycoplasma pneumonia group comprised 26 male and 24 female children aged $6.2 \pm 3.1$ years. The control group comprised 27 male and 23 female children aged $6.7 \pm 3.8$ years. There was no significant difference in the general information among the 3 groups $(\mathrm{P}>0.05)$.

\section{Methodology}

Peripheral venous blood was collected in the morning and routine blood, IL-6, and PCT tests were conducted. The blood samples were tested within 30 minutes to 2 hours. Blood routine tests were measured by Sysmex XE2100 automatic blood cell analyzer, and the IL-6 and PCT levels were determined using the Roche Cobase 601 automatic immune analyzer. All the operation steps were carried out in strict accordance with the instructions in the kits. The diagnostic criteria for children's pneumonia are based on the Guidelines for the Diagnosis and Treatment of Children's Community-acquired Pneumonia (2019 edition), which issued by the General Office of the National Health Commission of China. Items which assess the degree of the children's pneumonia include general condition, disturbance of consciousness, hypoxemia, temperature, dehydration/antifeedant symptoms, pulmonary imaging, and extrapulmonary complication.

All procedures performed in this study involving human participants were in accordance with the Declaration of Helsinki (as revised in 2013). The study was approved by 

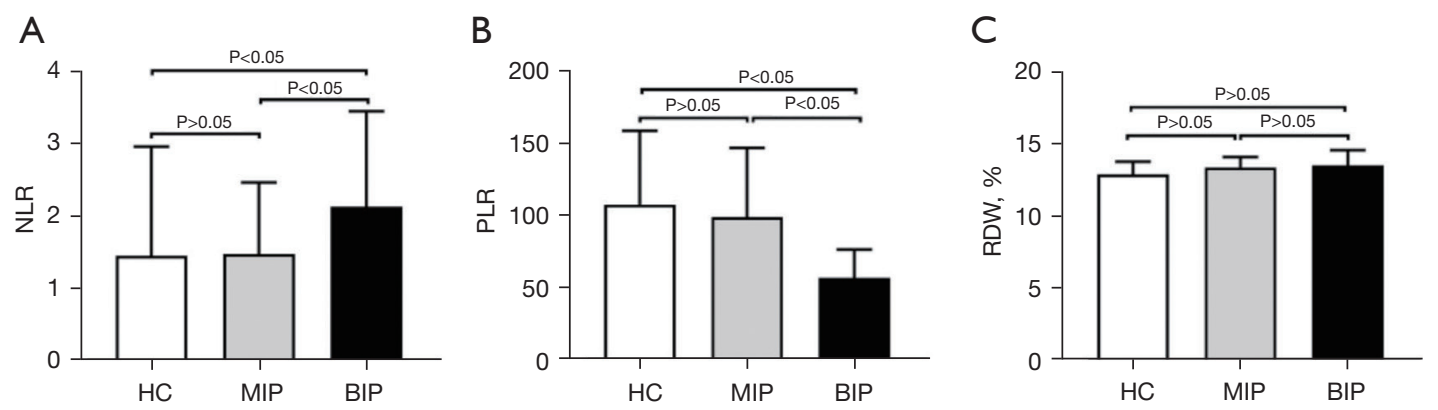

Figure 1 The NLR, PLR, and RDW index values for the 3 groups of children. HC, healthy control; MIP, mycoplasma pneumonia; BIP, bacterial pneumonia; NLR, neutrophil count/lymphocyte count ratio; PLR, platelet count/lymphocyte count ratio; RDW, red cell distribution width.

the ethics board of the Second Affiliated Hospital of Anhui Medical University [No. YW2020-135(F1)] and individual consent for this retrospective analysis was waived.

\section{Statistical analysis}

The data were statistically analyzed using SPSS for Windows 20.0 software. The Mann-Whitney test was used to compare 2 groups of data, and the Spearman correlation test was used to analyze correlations between different indicators. To evaluate the clinical value of the NLR, PLR, and RDW index in the diagnosis of bacterial pneumonia in children, the areas under the curve (AUCs) were obtained by a ROC curve analysis using MedCalc for Windows software. A P value $<0.05$ was considered statistically significant.

\section{Results}

The NLR, PLR, and RDW Index values in bealthy children, children with mycoplasma pneumonia, and children with bacterial pneumonia

The NLR values of the healthy children, children with mycoplasma pneumonia, and children with bacterial pneumonia were $1.45 \pm 1.51,1.47 \pm 0.98$, and $2.13 \pm 1.32$, respectively. The PLR values of the healthy children, children with mycoplasma pneumonia, and children with bacterial pneumonia, were $107.68 \pm 51.28,99.05 \pm 48.06$, and $56.97 \pm 19.55$, respectively. The RDW index values of the healthy children, children with mycoplasma pneumonia, and children with bacterial pneumonia were $12.89 \pm 0.88,13.16 \pm 0.94$, and $12.93 \pm 1.04$, respectively. Further statistics showed that the NLR of children with bacterial pneumonia was significantly higher than that of children with mycoplasma pneumonia and healthy children $(\mathrm{P}<0.05$; see Figure $1 A)$. The PLR of children with bacterial pneumonia was significantly lower than that of children with mycoplasma pneumonia and healthy children $(\mathrm{P}<0.05$; see Figure $1 B)$. There was no significant difference $(\mathrm{P}>0.05)$ in the RDW index values among the healthy control, mycoplasma pneumonia, and bacterial pneumonia groups (see Figure 1C).

\section{Correlations of the NLR, PLR, and RDW with IL-6 and PCT in children with bacterial pneumonia}

The NLRs and PLRs of children with bacterial pneumonia were significantly different from those of healthy children and children with mycoplasma pneumonia. To explore the significance of these changes, we further analyzed the correlations between the NLR, PLR, RDW index, and inflammatory markers in children with bacterial pneumonia (Figure 2), and found that the NLR was positively correlated with serum IL-6 $(\mathrm{R}=0.203 ; \mathrm{P}=0.041$; see Figure $2 A)$ and the PLR was negatively correlated with serum PCT $(\mathrm{R}=-0.291$; $\mathrm{P}=0.037$; see Figure 2D), while $\mathrm{RDW}$ was not significantly correlated with either serum IL-6 $(\mathrm{R}=0.077 ; \mathrm{P}=0.615)$ or serum PCT $(\mathrm{R}=0.048 ; \mathrm{P}=0.763)$ (see Figure 2E,2F).

\section{Clinical values of the NLR, PLR, and RDW index in the diagnosis of bacterial pneumonia in children}

We undertook a ROC curve analysis to examine the clinical value of the NLR, PLR, and RDW index in the differential diagnosis of healthy children and children with bacterial pneumonia. The AUCs for the NLR, PLR, and RDW index were 0.767 [95\% confidence interval (CI): 0.664-0.850], 0.898 (95\% CI: 0.815-0.953), and 0.676 (95\% 

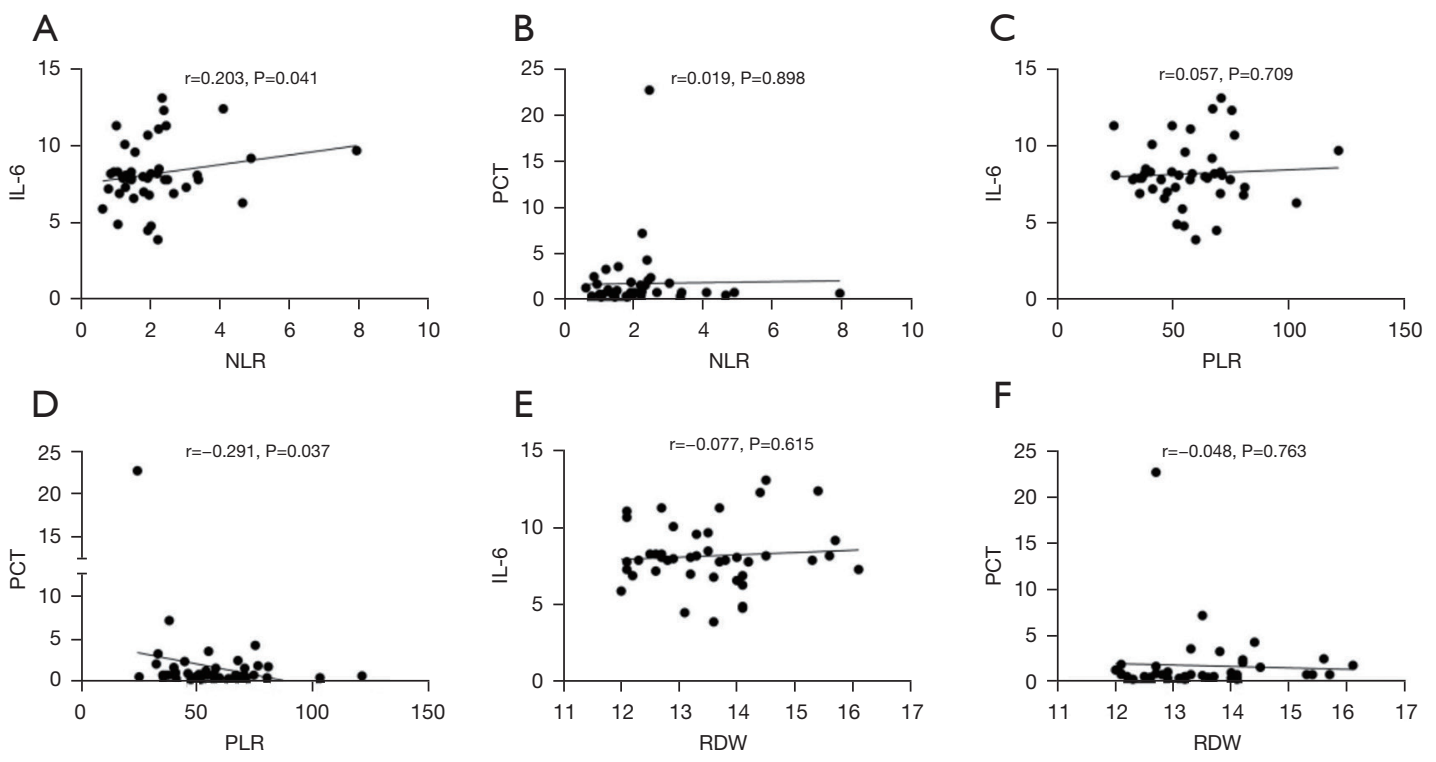

$\mathrm{F}$

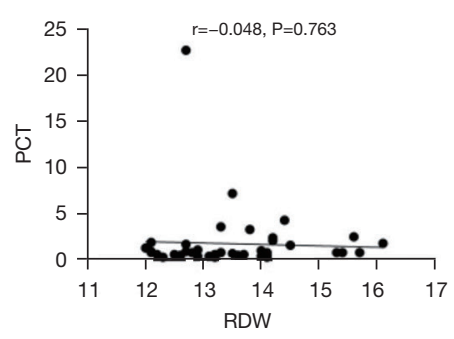

Figure 2 Correlations of the NLR, PLR, and RDW index with inflammatory markers in children with bacterial pneumonia. (A,B) Correlation of the NLR with IL-6 (A) and PCT (B); (C,D) correlation of the PLR with IL-6 (C) and PCT (D); (E,F) correlation of the RDW index with IL-6 (E) and PCT (F). NLR, neutrophil count/lymphocyte count ratio; PLR, platelet count/lymphocyte count ratio; RDW, red cell distribution width; IL-6, interleukin 6; PCT, procalcitonin.
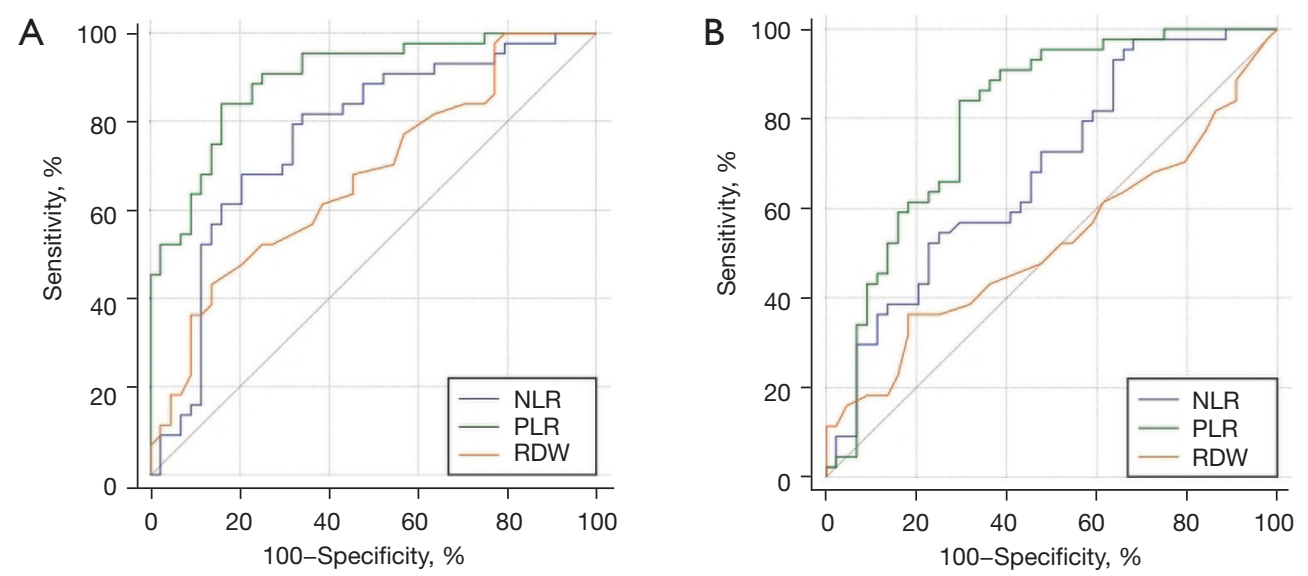

Figure 3 ROC curve analysis of the clinical value of the NLR, PLR, and RDW index in the diagnosis of bacterial pneumonia in children. (A) AUC for the differential diagnosis of bacterial pneumonia in healthy children and children; (B) AUC for the differential diagnosis of mycoplasma pneumonia and pediatric bacterial pneumonia. NLR, neutrophil count/lymphocyte count ratio; PLR, platelet count/ lymphocyte count ratio; RDW, red cell distribution width; AUC, area under the curve.

CI: 0.568-0.772), respectively. Thus, the PLR differential diagnosis had the greatest clinical value (see Figure $3 A$ ). When the PLR was 71.22 , the specificity and sensitivity were $84.09 \%$ and $88.36 \%$, respectively. We also examined the clinical value of the NLR, PLR, and RDW index in the differential diagnosis of mycoplasma pneumonia and bacterial pneumonia in children. The AUC of the NLR, PLR, and RDW index were 0.685 (95\% CI: 0.577-0.780), 0.803 (95\% CI: $0.577-0.780$ ), and 0.522 (95\% CI: $0.577-$ $0.780)$, respectively. Again, the PLR had the greatest clinical value in the differential diagnosis (see Figure 3B). When the PLR was 71.26 , the specificity and sensitivity were $84.63 \%$ 
and $70.45 \%$, respectively.

\section{Discussion}

In recent years, hematological markers have gradually begun to be used in the clinical diagnosis and prognosis of infectious diseases, and the NLR and PLR have been proposed as indicators of systemic inflammation and infection $(7,8)$. It is now clear that the NLR is an important index that reflects the activation of inflammatory cells. An elevated NLR often indicates the upregulation of neutrophils and the enhancement of the intensity of action in patients (9). Studies by foreign scholars have shown that the greater the NLR value, the higher the severity of the pneumonia (10). Other studies have shown that the PLR reflects the degree of platelet activation, which is related to infectious, hematological, and immune diseases. The higher the PLR, the higher the degree of platelet activation. The RDW index is a routine detection index used in whole blood cell analysis that reflects the variability of red blood cell volume. In the past, it was mainly used to judge the type of anemia and for differential diagnosis. Today, the RDW index is considered an important indicator of the degree of inflammation. The results showed that the NLR value was significantly higher and the PLR value was significantly lower in children with bacterial pneumonia than children with mycoplasma pneumonia and healthy children. Notably, there was no significant difference in the RDW index value among the healthy control, mycoplasma pneumonia, and bacterial pneumonia groups, which suggests that the NLR and PLR may have clinical value in the differential diagnosis of bacterial pneumonia.

IL-6 is a pleiotropic cytokine with a wide range of functions that can regulate the immune response, the acute phase response, and hematopoietic function, and that plays an important role in the body's anti-infective immune response (11). Serum PCT has a high level of stability in the human body, but severe bacterial infection or acute bacterial infection can make serum PCT rise sharply within 4 hours (12). The level of PCT is positively correlated with the type of pathogen and the severity of the infection (13). Our correlation analysis revealed that the NLR was positively correlated with serum IL-6, while the PLR was negatively correlated with serum PCT in children with bacterial pneumonia. Notably, the RDW index was not significantly correlated with serum IL-6 or serum PCT. The ROC curve analysis revealed that the RDW, NLR and PLR had clinical value in the differential diagnosis between bacterial pneumonia and healthy children, but the PLR had the greatest clinical value. In the differential diagnosis of mycoplasma pneumonia and pediatric bacterial pneumonia, only the PLR had clinical value. Compared with other etiological detection (mycoplasma antibody, respiratory virus detection, Macro Gene Detection, bacterial culture), PLR in the use of Convenient and easy to do, so it can provide some reference for doctors in the early treatment. The most important things are to reduce the abuse of antibiotics and bacterial resistance. The advantages of PLR in the diagnosis of children's pneumonia are as following: determine treatment as soon as possible, low cost, detection can be sent at any time; Notably, it has been reported that cardiovascular system events (e.g., heart valve disease, infectious endocarditis, hypertension, and coronary artery disease), appendicitis, endocrine diseases (e.g., diabetes mellitus, and thyroid disease), liver and kidney dysfunction, and other diseases can affect the NLR and PLR values of patients (14). Thus, it is necessary to exclude other systemic diseases when using these indexes in the diagnosis of bacterial pneumonia in children.

In sum, this study compared differences among the NLR, PLR, and RDW index values in children with mycoplasma pneumonia and children with bacterial pneumonia, and found that the PLR has certain clinical value in the diagnosis of children with bacterial pneumonia. However, the sample size of this study was small, and it was a single-center study; thus, there may be sample selection bias. Large-sample and multi-center studies need to be conducted to gather further evidence of the value of the indexes in the clinical treatment of children with bacterial infectious pneumonia.

\section{Acknowledgments}

Funding: The study was supported by Project of pediatrics and Immunology (No. 2021LCXK030).

\section{Footnote}

Reporting Checklist: The authors have completed the STARD reporting checklist. Available at https://tp.amegroups.com/ article/view/10.21037/tp-21-568/rc

Data Sharing Statement: Available at https://tp.amegroups. com/article/view/10.21037/tp-21-568/dss

Conflicts of Interest: All authors have completed the ICMJE 
uniform disclosure form (available at https://tp.amegroups. com/article/view/10.21037/tp-21-568/coif). The authors have no conflicts of interest to declare.

Ethical Statement: The authors are accountable for all aspects of the work in ensuring that questions related to the accuracy or integrity of any part of the work are appropriately investigated and resolved. All procedures performed in this study involving human participants were in accordance with the Declaration of Helsinki (as revised in 2013). The study was approved by the ethics board of the Second Affiliated Hospital of Anhui Medical University [No. YW2020-135(F1)] and individual consent for this retrospective analysis was waived.

Open Access Statement: This is an Open Access article distributed in accordance with the Creative Commons Attribution-NonCommercial-NoDerivs 4.0 International License (CC BY-NC-ND 4.0), which permits the noncommercial replication and distribution of the article with the strict proviso that no changes or edits are made and the original work is properly cited (including links to both the formal publication through the relevant DOI and the license). See: https://creativecommons.org/licenses/by-nc-nd/4.0/.

\section{References}

1. Xin H, Li J, Hu HY. Is Lung Ultrasound Useful for Diagnosing Pneumonia in Children?: A Meta-Analysis and Systematic Review. Ultrasound Q 2018;34:3-10.

2. Nicolaou EV, Bartlett AH. Necrotizing Pneumonia. Pediatr Ann 2017;46:e65-8.

3. Bin ST, Li Ming, Tan Li, et al. Clinical Analysis of 46 Children with Necrotizing Pneumonia. Journal of Kunming Medical University 2021;42:124-9.

4. Leung AKC, Wong AHC, Hon KL. Community-Acquired Pneumonia in Children. Recent Pat Inflamm Allergy Drug Discov 2018;12:136-44.

5. Liu Wang, Wang RY, Cheng MY. Research progress of red

Cite this article as: Zheng $\mathrm{HH}$, Xiang $\mathrm{Y}$, Wang Y, Zhao QS, Fang R, Dai R. Clinical value of blood related indexes in the diagnosis of bacterial infectious pneumonia in children. Transl Pediatr 2022;11(1):114-119. doi: 10.21037/tp-21-568 blood cell distribution width in diagnosis and treatment of lung diseases and prognosis. Journal of Hainan Medical University 2021;27:315-20.

6. Li X, Liu JB, Han XP, et al. Value of platelet-lymphocyte ratio in predicting the prognosis of community-acquired pneumonia. Chinese General Practice 2019;22:659-63

7. Chen QQ, Huo JM. Correlation between neutrophillymphocyte ratio and CAP severity score. Journal of Clinical Pulmonary Medicine 2020;25:34-9.

8. Kartal O, Kartal AT. Value of neutrophil to lymphocyte and platelet to lymphocyte ratios in pneumonia. Bratisl Lek Listy 2017;118:513-6.

9. Tian M, Cao DL. Predictive value of neutrophil to lymphocyte ratio, procalcitonin in assessing the severity and prognosis in patients with community acquired pneumonia. Journal of China Prescription Drug 2021;19:163-4.

10. Che-Morales JL, Cortes-Telles A. Neutrophil-tolymphocyte ratio as a serum biomarker associated with community acquired pneumonia Rev Med Inst Mex Seguro Soc 2019;56:537-43.

11. Wang J, Song Y, Li W. Application value of the detection of serum levels of TNF- $\alpha$, IL-6, CRP, sICAM-1 and PCT in evaluating the severity of children with severe pneumonia. Hebei Medical Journal 2021;43(6):876-8.

12. Special Committee of Hospital Infection Management and Control, the Society of Pediatrics, Chinese Medical Association. Expert consensus on clinical application of serum procalcitonin in pediatric infectious disease. Zhonghua Er Ke Za Zhi 2019;57:9-15.

13. Zhang LH, Yi TT, Xu YJ. Diagnostic value of serum IL-6, PCT and hs-CRP expression in newborn with bacterial pneumonia. Chinese Journal of Nosocomiology 2020;30:453-7.

14. Ozaksit G, Tokmak A, Kalkan H, et al. Value of the platelet to lymphocyte ratio in the diagnosis of ovarian neoplasms in adolescents. Asian Pac J Cancer Prev 2015;16:2037-41.

(English Language Editor: L. Huleatt) 